\title{
A ESTRANGEIRIDADE E A AUTORREPRESENTAÇÃO COMO PERFORMATIVIDADE NARRATIVA DE GÊNERO EM CLARICE LISPECTOR
}

\author{
Anderson Gomes Paes Barretto ${ }^{1}$
}

\begin{abstract}
Resumo
O artigo busca inicialmente relacionar Clarice Lispector à noção de estrangeiridade, proposta por Julia Kristeva, para exemplificar a clandestinidade da mulher escritora na patriarcal sociedade brasileira. Nesse sentido, o jogo narrativo masculino/feminino da obra A Hora da Estrela (1977) é analisado à luz da noção de performatividade, proposta por Judith Butler, para entender a autorrepresentação como ferramenta válida para fazer ecoar a afirmação feminina diante dessa histórica abjeção. Por fim, a personagem Macabéa é apontada como uma irônica reação da autora à estrutural misoginia do meio literário brasileiro, visto que a personagem desterritorializa as habituais reduções da figura da mulher e tem a legitimação de sua existência condicionada à autoridade narrativa de um eu masculino, que é, na verdade, Clarice Lispector.
\end{abstract}

\section{Palavras-chave}

Estrangeiridade. Literatura e Resistência. Autorrepresentação. Performatividade. Clarice Lispector.

\section{1) Introdução}

Nascida no despertar da década de 1920, Clarice Lispector (1920-1977) viveu em uma época de mudanças sociais, políticas e culturais que marcaram sua vida e sua obra: a eclosão de estéticas nacionalistas e regionalistas dentro da literatura brasileira, além do nascimento de movimentos sociais como o feminismo e a luta contra a ditadura militar instalada no país, cujo fim a escritora não chegou a ver. Clarice começou sua vida profissional no Rio de Janeiro a partir da década de 1940 como jornalista na Agência Nacional, organização criada no governo de Getúlio Vargas. A escritora adentrou um espaço majoritariamente ocupado por homens, o das redações jornalísticas, o que fez com que Clarice, desde o início da sua vida profissional como tradutora, jornalista e redatora, desenvolvesse um olhar aguçado sobre o cotidiano. Para Gotlib (2011, p. 170), a atividade

\footnotetext{
${ }^{1}$ Bacharel em Comunicação Social, mestre e doutorando em Comunicação pela Universidade Federal de Pernambuco (UFPE). Autor da dissertação "Clarice Lispector da Literatura para o Cinema: adaptação, narrativa e crítica social em A Hora da Estrela" (2016), sob a orientação da Profa. Dra. Carolina Dantas de Figueiredo.
} 
jornalística de Clarice teve início entre 1940 e 1941, mas só obteve registro em 1942, tendo a sua atividade reconhecida em sua primeira carteira de trabalho.

\section{2) A estrangeiridade de Clarice Lispector e da mulher na literatura}

Por ter se casado com um diplomata, Clarice conheceu o mundo, morou em diversas cidades como Lisboa, Roma, Berna, Washington e tantas outras, fato que a ajudou a construir um olhar constantemente desterritorializado, marcado pelo desconforto do não pertencimento, de um lado pela sua origem estrangeira, de outro, pelos seus constantes movimentos migratórios. Esse seu olhar distanciado, estrangeiro, contribuiu para o desenvolvimento de uma obra universal e transtemporal que a coloca no patamar das grandes personalidades literárias de todos os tempos. Nascida na Ucrânia, num contexto familiar de migração para o Brasil, a brasileira detalha sobre a sua origem:

Nasci na Ucrânia, terra de meus pais. Nasci numa aldeia chamada Tchechelnik, que não figura no mapa de tão pequena e insignificante. Quando a minha mãe estava grávida de mim, meus pais já estavam se encaminhando para os Estados Unidos ou Brasil, ainda não haviam decidido: pararam em Tchechelnik para eu nascer, e prosseguiram viagem. Cheguei ao Brasil com apenas dois meses de idade. (LISPECTOR, 2008, p. 345)

Clarice se considerava brasileira, pois, segundo relatos da própria, veio recémnascida ao Brasil e jamais chegou a pisar em sua cidade natal. Dizia ser de Recife, cidade em que passou a infância ${ }^{2}$ e de onde saiu aos catorze anos para morar no Rio de janeiro junto com a família. Em 1943, Clarice se casou com Maury Gurgel Valente, seu colega na faculdade de Direito que veio a ser diplomata e com quem teve dois filhos: Pedro, nascido na cidade de Berna em 1949, e Paulo, nascido em Washington em 1953. De fato, todo o contexto familiar de Clarice reforça a sua estrangeiridade essencial. Mais do que uma característica física ou geográfica, a estrangeiridade é uma condição que é, inclusive, identificada em outros escritores da língua portuguesa como por exemplo Fernando Pessoa e Carlos Drummond de Andrade ${ }^{3}$.

\footnotetext{
${ }^{2}$ Durante a infância, Clarice teve que lidar com a morte de sua mãe, quando tinha apenas nove anos de idade. Esse fato, segundo Guidin (2002), veio a influenciar a obra da escritora em obras como Perto do coração selvagem, Uma aprendizagem ou o livro dos prazeres e também A hora da estrela, cuja protagonista é órfã de pai e mãe.

${ }^{3}$ Em Drummond, o termo gauche foi largamente utilizado para falar de si mesmo em variados versos que tentavam reproduzir o seu não pertencimento e deslocamento existencial no mundo. Já Fernando Pessoa se utilizou de seus múltiplos heterônimos para dar conta de toda a sua versatilidade e desterritorialização existencial.
} 
Para Kristeva (1994, p. 15), o estrangeiro é aquele que tem como característica o fato de "não pertencer a nenhum lugar, nenhum tempo, nenhum amor". O ser estrangeiro é aquele que vive em trânsito, isto é, carrega a marca do deslocamento dentro do mundo, a estranheza dentro do cotidiano. A sua origem é perdida e o seu presente é suspenso, ou seja, “o espaço do estrangeiro é um trem em marcha, um avião em pleno ar, a própria transição que exclui a parada. Pontos de referência, nada mais" (KRISTEVA, 1994, p. 15).

Indo por esse mesmo caminho de Kristeva, Bauman (2005) faz um relato no qual se pode identificar a sua condição de estrangeiridade aqui identificada em Clarice. Assim como a escritora, Bauman era judeu e havia fugido da União Soviética durante um período de guerra:

Em todo e qualquer lugar eu estava - algumas vezes ligeiramente, outras ostensivamente - deslocado. (...) Estar total ou parcialmente "deslocado" em toda a parte, não estar totalmente em lugar algum (ou seja, sem restrições e embargos, sem que alguns aspectos da pessoa "se sobressaiam" e sejam vistos por outras como estranhos), pode ser uma experiência desconfortável, por vezes perturbadora. (BAUMAN, 2005p. 18).

Apesar de compartilhar dessa estrangeiridade, Clarice, diferentemente de Bauman, não reconhecia o seu país natal como definidor de sua nacionalidade. Além disso, as constantes mudanças de endereço ao longo dos 16 anos em que esteve casada, resulta na constatação de uma vida "entre a necessidade de pertencer e a tenaz insistência de manter-se à parte" (MOSER, 2011, p. 22). A nacionalidade brasileira da escritora só veio aos 23 anos, em virtude de seu casamento na época próxima à publicação de seu primeiro livro, Perto do coração selvagem (1943). Isso certamente contribuiu para que o sentimento de "não pertencer" que a escritora carregava desde a sua juventude fosse perpetuado para toda a sua existência, o que, de acordo com Santos (2000, p. 19), influenciou na manutenção de uma literatura melancólica, nostálgica e memorialista.

O romance de estreia de Clarice seguiu um caminho diferente do que era comum na época de sua publicação, início da década de 1940. Gotlib (2011, p. 204) afirma que o estilo de sua escrita foi prontamente associado a escritores estrangeiros como James Joyce, Katherine Mansfield e Virginia Woolf, especialmente pela sua abordagem íntima de questões pouco comuns na literatura do Brasil naquela época, dominada pelo regionalismo, sobretudo, escrito por homens. Desse modo, a escrita de Clarice desde o 
início foi recebida com um olhar desconfiado, que a percebia como uma escritora menor, outsider.

Para Elias e Scotson (2000, p. 20), o outsider é aquele indivíduo que não pertence ao grupo social privilegiado e, portanto, é marginalizado e excluído por aqueles que detêm o poder, os chamados estabelecidos. Estes, por sua vez, não apenas legitimam quem pertence e quem não pertence, como também promovem a manutenção da sua condição dominante, de modo a estigmatizar os outsiders. Ao terem sua superioridade afirmada, os estabelecidos buscam a todo instante maneiras de preservação de suas identidades soberanas e, consequentemente, meios de diminuição e até de desumanização dos outsiders. Nesse sentido, Butler (2018a, p. 94) reforça que a regulação dos corpos e subjetividades está diretamente relacionada à subordinação presente na normalização, de modo que os indivíduos destoantes e excluídos do grupo soberano, são prontamente enquadrados como uma espécie descartável.

Até hoje a literatura escrita por mulheres luta para estar na categoria "estabelecida", apesar de inúmeros nomes de escritoras mulheres que contribuíram e contribuem para a legitimação da literatura brasileira. Uma prova dessa aversão normativa à mulher na literatura é a manutenção do estabelecimento masculino na Academia Brasileira de Letras (ABL), instituição fundada em 1897, historicamente machista e acostumada ao não reconhecimento da literatura feminina no país. De acordo com Ruy (2016, Online) até 1951, a ABL possuía em seu estatuto a inclusão de membros "brasileiros" que tivessem publicado obras de reconhecido mérito ou livro de valor literário - normatização que ficou praticamente oito décadas em vigor. Em 1930, ano da primeira candidatura feminina, Amélia Beviláqua foi rejeitada sob o pretexto de que o vocábulo "brasileiros" seria supostamente restrito ao "sexo masculino" (RUY, 2016, Online). Essa postura machista se tornou explícita no início dos anos 1950, quando o regimento da $\mathrm{ABL}$ deixava evidente que somente os seus membros efetivos "do sexo masculino" poderiam ser eleitos. A segunda mulher a tentar participar do círculo de literatos imortais foi Dinah Silveira Queiroz, rejeitada em 1971. A sua rejeição abriu caminhos para protestos em defesa da inclusão das mulheres na instituição, de modo que em 1977, Rachel de Queiroz se tornou a primeira mulher a ser aceita entre os imortais. Dinah foi novamente rejeitada em 1979, sendo aceita finalmente em sua terceira candidatura, que aconteceu em 1980. A terceira mulher a ser membro da ABL foi Lygia Fagundes Telles, em 1985, seguida por Nélida Piñon em 1989, Zélia Gattai em 2001, Ana 
Maria Machado em 2003, Cleonice Berardinelli em 2009 e por fim Rosiska Darcy em 2013. Atualmente as mulheres ocupam apenas quatro (de quarenta) cadeiras na ABL.

Clarice Lispector, apesar se ser uma escritora canônica, jamais teve a chance de ser membro da ABL, uma vez que morreu no ano em que a primeira mulher foi aceita pela instituição. Em 2017, a ABL, cuja coordenação geral estava nas mãos da acadêmica Ana Maria Machado, encerrou o evento "Cadeira 41" com a conferência "O legado de Clarice Lispector", proferida pela pesquisadora e biógrafa de Clarice, Nádia Gotlib. A conferência teve como objetivo defender o nome de Clarice Lispector como digno de pertencer a uma das quarentas cadeiras da ABL. De acordo com o site da ABL (2017), entre os homenageados nas demais conferências do evento estava o nome de mais uma mulher, Júlia Lopes de Almeida, fundadora da Academia Brasileira de Letras que, no entanto, jamais foi considerada membro.

Apesar dessa exclusão histórica da mulher na literatura brasileira, Clarice Lispector se manteve fiel ao ofício de escritora e ao seu modo de narrar, marcado pela apreensão artística da realidade "feita a partir da consciência individual, não coletiva" (GUIDIN, 2002, p.24). Clarice acaba assim fortalecendo uma estética que privilegia a expressividade das palavras e ao lado de Guimarães Rosa, determina um terceiro momento do Modernismo, quando "o gênero romance deixa seu modelo tradicional, em que estão o Brasil regional e o realismo cru, para ganhar nova dimensão e outra finalidade, como a de registrar a problematização estética da linguagem, discutindo, assim, os próprios limites do gênero" (ibid, p.25).

No entanto, Clarice era criticada por supostamente não retratar em suas obras a condição social do povo brasileiro. Guidin (2002, p. 28) ressalta que a crítica acusava a escritora de evitar um olhar sociopolítico sobre a realidade do país. Nesse sentido, Moser (2011, p.25) acrescenta que a singularidade de Clarice perturbava as pessoas, ao ponto de ela ser acusada até mesmo de alienação, sendo considerada estranha não apenas por conta de seu sobrenome incomum, como também por conta de sua fala esquisita - na verdade, um problema de dicção. Soma-se a isso as suas referências a objetos e costumes de outros países, de modo que a permanência de escritora em cidades de outros países só contribuía para estimular essa imagem que se costumava fazer dela.

Diversos fatos históricos dentro e fora do Brasil fortaleciam a postura defendida pelos intelectuais da época de que a literatura tinha a obrigação de mostrar engajamento político: o golpe militar de 1964, a Guerra do Vietnã (1955-1975), a extinção da União Nacional dos Estudantes (UNE) em 1968, além do próprio endurecimento da ditadura 
militar entre 1967 e 1969. Para Pécaut (1990, p. 251), foi nesse contexto que o meio intelectual brasileiro se transformou num subuniverso político, em que a cultura de oposição cresceu especialmente por meio de manifestações artísticas.

Dos espetáculos do teatro de Arena às comédias musicais do Opinião, do festivais da canção aos filmes do Cinema Novo, do Tropicalismo aos happenings nas artes plásticas, tudo é motivo para a participação de um público considerável (...) portador de uma linguagem contestadora. (PÉCAUT, 1990, p.251)

Clarice Lispector, que já havia retornado definitivamente ao Brasil em 1959, após se separar do marido, trabalhava como tradutora, além de cronista para jornais e revistas. Isso a fez se aproximar mais do seu público leitor, afinal, o fato de a escritora ser publicada num jornal fez com que ela passasse a ter um maior contato com seus leitores, cujas cartas chegavam à redação constantemente, sendo respondidas pela escritora até mesmo em suas próprias publicações. Colunas como "Correio feminino", no jornal Correio da Manhã, e "Entre mulheres", no tabloide Comício, fizeram parte da trajetória da escritora nas seções escritas por mulheres dentro da mídia jornalística brasileira. (GOTLIB, 2011)

Nunes (2006, p. 10) diz que ao seguir o caminho dos textos escritos por mulheres, que pregavam um discurso aparentemente inofensivo e em conformidade ao status quo, Clarice se utilizava de conselhos, receitas e segredos para desenvolver o hábito de leitura nas mulheres. Dessa forma, a escritora transformava as páginas de jornais em verdadeiros espaços de diálogo, instigando suas leitoras a refletirem sobre a condição da mulher na sociedade da época, situada entre as simulações do cotidiano e a própria realidade.

Nesse percurso, a íntima relação de Clarice com a crônica abriu as portas para uma percepção mais aproximada da vida do povo brasileiro, sobretudo, diante das tragédias do cotidiano. Em 1962, por exemplo, a escritora publicou a crônica "Mineirinho", em que se mostrou chocada com o exagero e a prepotência dos policiais que mataram um bandido com abusivos treze tiros, fato amplamente noticiado na época. Nesse texto, a autora faz um percurso em que coloca a si mesma no lugar do criminoso:

Esta é a lei. Mas há alguma coisa que, se me fez ouvir o primeiro e o segundo tiro com um alívio de segurança, no terceiro me deixa alerta, no quarto desassossegada, o quinto e o sexto me cobrem de vergonha, o sétimo e o oitavo eu ouço com o coração batendo de horror, no nono e no décimo minha boca está trêmula, no décimo primeiro digo em espanto o nome de Deus, no décimo segundo chamo meu irmão. $\mathrm{O}$ 
décimo terceiro tiro me assassina - porque eu sou o outro. Porque eu quero ser o outro. (LISPECTOR, 1999, p.124)

Na década de 1970, o engajamento político ganha ainda mais força no país, sobretudo como reação à ditadura militar. Pécaut (1990, p. 255) diz que a intelectualidade do país assumiu nesse momento de crise o papel de ator político, de modo que termos e expressões como "democracia" e "sociedade civil" se tornaram comuns nos mais variados discursos. É nessa época que a escrita de Clarice começa também a se aproximar mais das questões sociais, de modo que as injustiças, a desigualdade e as disparidades de gênero, que sempre fizeram parte de sua percepção de mundo, começam a se mostrar mais fortemente em seu projeto estético.

Nesse período, começa no país um intenso debate sobre alteridade, que ganha força "a partir dos movimentos anticoloniais, étnicos, raciais, de mulheres, de homossexuais e ecológicos que se consolidam como políticas emergentes" (HOLLANDA, 1994, p. 8). É nesse terreno que Clarice também passa a plantar a sua literatura que, ao contrário do que dizia a crítica da época, estimula um olhar da própria autora e também de seus leitores sobre o outro, especialmente sobre o universo da mulher.

De fato, a obra de Clarice é marcada pela construção da figura da mulher como elemento fundamental do seu texto, mas ela vai além disso. Na verdade, a sua escrita traz à tona "uma forte crítica à sociedade patriarcal e machista em que estava inserida (e que perdura até os dias atuais), além de revelar uma de suas maiores inquietações: a condição da mulher nessa sociedade”. (MENEZES, 2017, p. 329)

\section{3) As Macabéas do mundo}

Com a novela $A$ hora da estrela (1977), última obra publicada em vida pela escritora, Clarice conseguiu expor o contexto de miséria de grande parte da sociedade brasileira: a realidade das mulheres migrantes, nordestinas, invisibilizadas e excluídas das discussões sociais, políticas, econômicas, culturais e de gênero no país. Ao se vestir de sua personagem Macabéa, Clarice revela profundo conhecimento da realidade da época, excludente e redutora da mulher, especialmente no contexto da migração nordestina, cuja população era, no máximo, usada como mão-de-obra barata nas grandes cidades do sudeste e sul do país. A autora sabia disso por experiência própria: a sua história pessoal, estrangeira, é marcada por movimentos migratórios, tendo ela mesma saído do Nordeste brasileiro para morar em várias regiões do mundo até se estabelecer definitivamente no Rio de Janeiro. Clarice reconhecia também a dificuldade de existir, de pertencer, de 
aceitar a si mesmo como ser vivente em uma sociedade patriarcal. Por essa razão, a escritora buscou representar em Macabéa a realidade traçada para as mulheres por essa construção social de submissão e invisibilidade das mulheres. Com Macabéa, Clarice não mais se dedicava a reforçar estereótipos das "páginas femininas", geralmente fadadas à banalidade e à frivolidade do cotidiano, nas quais se reproduziam comportamentos pertencentes a uma feminilidade reduzida ao lar, à maternidade e à manutenção da beleza. Com Macabéa, Clarice mostrou o outro lado de sua escrita e decidiu personificar a si mesma como uma voz destinada a direcionar a atenção da sociedade para uma forma pouco comum de resistência: a da autorrepresentação.

Butler (2017, p. 22) diz que o relatar a si mesmo é um ato de resposta a uma interpelação, uma vez que os indivíduos em sociedade são obrigados a isso por um sistema de justiça e castigo. Ou seja, os indivíduos estão submetidos a um regime de verdade que determina quem é reconhecível e quem não é no meio social, logo, fazer um relato de si significa dizer a verdade sobre si mesmo como forma de resposta ao julgamento do outro. Butler (2017, p. 22-23) evoca Nietzsche para lembrar que a necessidade de fazer um relato de si só surge depois de uma acusação, a partir da qual o indivíduo passa a refletir sobre si mesmo, o que por outro lado o compele à responsabilidade sobre si mesmo. Dessa forma, o relato de si acaba sendo um reflexo representativo de toda uma coletividade, afinal, "quando o eu busca fazer um relato de si mesmo, pode começar consigo, mas descobrirá que esse "si mesmo" já está implicado numa temporalidade social que excede suas próprias capacidades de narração". (BUTLER, 2017, p. 18)

Ao se utilizar de Macabéa para relatar a si mesma, Clarice Lispector enuncia um potente discurso de resistência da mulher, nordestina, migrante, estrangeira, o que é feito a partir da afirmação da própria existência, universalizada em sua personagem. A escrita de Clarice é marcada pela reflexão sobre si, uma vez que sua escrita memorialista evidencia explicitamente o seu "estar no mundo", principalmente a partir das referências que utiliza em seus textos para reproduzir fatos e acontecimentos de sua vida. Logo, ao ser interpelada pela crítica que a acusava de omissão, a escritora retoma toda a sua trajetória literária e existencial para desembocar numa representação social brasileira e mundial em Macabéa. Ou como a autora mesma diz na dedicatória do livro: "explodir em: eu”. (LISPECTOR, 1998, p. 9)

Nesse caminho, Clarice parte para a representação de uma população castigada em vários sentidos, uma vez que a figura de Macabéa traduz e visibiliza inúmeras outras 
vidas de mulheres, nordestinas, des(norte)adas e descontextualizadas na urbanidade industrial das grandes metrópoles do país ${ }^{4}$. Macabéa é uma jovem de dezenove anos, miserável e inocente ao extremo, que simboliza a difícil adaptação e sobrevivência diante de um cenário socialmente desfavorável. Num primeiro olhar, Macabéa é a própria personificação da apatia, estrangeira num sentido além do geográfico. Para Kristeva (1994, p. 15), essa estrangeiridade está presente em todos nós, afinal, de certa forma, todos somos estrangeiros, a depender da perspectiva com que somos olhados. Nesse sentido, ao desenvolver a Macabéa, Clarice passava a olhar a si mesma.

Macabéa é uma personagem que quase não reage a nada, pouco se expressa, é alheia a tudo, tomada por uma espécie de invisibilidade estrutural herdada pela normatividade machista, patriarcal e colonial do Brasil. É uma personagem humilde e aparentemente simples que leva uma vida sem família, amores, amigos nem inimigos, ou seja, é uma mulher sozinha, perdida em todos os aspectos, incapaz até de relatar a si mesma, já que não tem sequer consciência de classe. A simples ausência de sobrenome da personagem já indica uma condição mesmo de desvinculação com possíveis raízes, condição compartilhada por tantos nordestinos na época. De fato, Macabéa era simplesmente ninguém:

Ela era incompetente. Incompetente para a vida. (...) Só vagamente tomava conhecimento da espécie de ausência que tinha de si em si mesma. Se fosse criatura que se exprimisse diria: o mundo é fora de mim, eu sou fora de mim. (LISPECTOR, 2008, p. 24)

Macabéa é a apatia personificada e, como Clarice, estrangeira em qualquer lugar, um traço que remete ao personagem Meursault, de Albert Camus em $O$ Estrangeiro ${ }^{5}$ (1942). Nessa obra, Camus conta a história de Meursault, um homem que vive na Argélia, região que até então pertencia à França; um homem que, ao viver sozinho, lida diariamente com o sentimento do não pertencer, em um misto de vazio existencial e apatia tão explícitos que chega a parecer frieza. Esse modo de ser do personagem, somado às circunstâncias de um contexto histórico abalado pelas guerras, o faz cometer um crime e ser condenado. As razões que levam o protagonista a isso não são muito claras, o que não descarta a hipótese de ele querer fugir da vida de algum modo. No fim do livro, Meursault,

\footnotetext{
${ }^{4}$ Para Baeninger (2005, p. 89), os deslocamentos populacionais no Brasil ocorridos desde os anos 1930 até a década de 1970 estiveram relacionados à transferência de população do meio rural para o urbano, um verdadeiro fenômeno da metropolização e consequente concentração urbana.

${ }^{5}$ Livro traduzido para o inglês como The Outsider.
} 
ao sentir que o universo é indiferente à humanidade, tem um desejo: "que houvesse muitos espectadores no dia de minha execução e que eles me recebessem com gritos de ódio" (CAMUS, 2006, p. 126). Num comparativo com A hora da estrela, a condenação de Mersault pode ser encarada como uma espécie de "hora", o momento de seu estrelato, onde a morte é o que o redime. O mesmo, afinal, acontece com Macabéa.

Mas, nesse caso, qual seria o crime de Macabéa? Ser mulher numa sociedade machista? Ser nordestina numa metrópole do Sudeste? Ser sozinha e órfã numa cultura que julga sua origem? Ser pobre? Ou mesmo todos esses “crimes”, uma vez que Macabéa é a materialização do "não ser", da vida nua, indigna de cidadania e empatia. Para Agamben (2010, p. 18), essa é uma vida não qualificada que pode e deve ser excluída, isto é, uma vida desprovida de garantias e exposta à morte. Numa sociedade materialista, que se contrapõe à literatura existencial de Clarice, o sonho de cultivar o que é anunciado, promovido, transformado em objeto de desejo e consumido pelos outros é uma grave infração. Logo, Macabéa é infratora ao comer o cachorro-quente com Coca-Cola, símbolos do império econômico estadunidense que o Brasil até hoje busca se espelhar. Ela é duplamente infratora quando ouve ópera na rádio relógio, uma vez que não tem o direito à cultura nem à informação. É infratora quando vai à cartomante e recebe notícias de um futuro próspero em que um homem rico, louro e de olhos azuis supostamente a livrará do seu destino de miséria. Macabéa é a mulher solitária, pobre, feia, nordestina, inculta e descartável que não tem direito ao casamento, ao amor, à riqueza, à beleza e a todo o contexto patriarcal materialista que seduz as subjetividades no âmbito da sociedade capitalista.

Nesse caminho, Macabéa (na verdade, Clarice Lispector) ao personificar uma vida nua, denuncia regimes de dominação presentes na sociedade. Na perspectiva dos indivíduos estabelecidos, cunhada por Elias e Scotson (2000, p. 24), Macabéa é a outsider por excelência, portanto, marginalizada e invisibilizada, incapaz de pertencer ao grupo social dominante, cujo poder só a exclui e estigmatiza.

\section{4) Autorrepresentação como performance}

Butler (2017, p. 18) diz que o "eu" não tem história própria que não seja uma história de relação, ou seja, não há como narrar a si mesmo sem carregar contextos de trocas sociais, culturais e, portanto, representativas. Nesse sentido, o relatar a si mesmo demanda não só a capacidade de transmitir informações e acontecimentos como também suscita uma autoridade narrativa que seja capaz de persuadir por meio da representação 
de si. Para Santaella (2000, p. 25), representação remete à significação e à verossimilhança, logo, a representação de si, ou a autorrepresentação, pode ser entendida como um caminho de convencer o outro por meio da identificação a partir das experiências de si. Dessa forma, o representar a si mesmo está diretamente relacionado ao relatar a si mesmo, uma vez que autorrepresentação pressupõe o controle de informações sobre si dentro do processo de reforço da própria identidade. De fato, "não há criação de si fora de um modo de subjetivação". (BUTLER, 2017, p. 29)

Clarice Lispector constrói a sua literatura de modo semelhante ao caminho do relatar a si mesmo de Butler, uma vez que, de modo geral, se utiliza de personagens que remetem à própria Clarice. Mas ela não faz isso apenas com o intuito de contar histórias vividas, mas sim com o objetivo de persuadir o leitor a respeito do seu papel no mundo tudo isso a partir da visão de alguém que de fato viveu aquelas histórias: ela mesma. Trata-se de uma espécie de autoridade narrativa baseada no vivido. De fato, "é dentro dos sistemas de representação da cultura e através deles que nós 'experimentamos o mundo', ou seja, a experiência é o produto de nossos códigos de inteligibilidade, de nossos esquemas de interpretação". (HALL, 2003, p. 171)

É nesse caminho que a autora cria personagens que parecem aceitar seus papéis sociais, mas que, na verdade, estimulam a refletir sobre si mesmo e assim questionar o seu lugar no mundo. Com Macabéa, Clarice faz justamente isso: ao relatar a si mesma por meio da narração da história da personagem, instiga a questionar a sua própria condição social. Nesse sentido, a autorrepresentação seria então uma forma potente de fazer ressoar o reconhecimento da própria identidade, e desse modo, estimular o olhar para si e para o outro, sobretudo numa sociedade que, para Landowski (2019, p. 27), é historicamente tomada por crises de alteridade.

Zumthor (2014, p. 52) diz que todo texto pressupõe leitura, logo, toda escrita se desenvolve mediante um horizonte de expectativas de alguém que não apenas decodifica o texto como o ressignifica por meio de um envolvimento sensorial. Esse envolvimento com o texto, por sua vez, evoca uma corporeidade da persona cuja voz é a que narra. Sendo assim, tomando como base o fato de que o corpo seria a materialização do eu enquanto realidade vivida, a leitura de um texto pode ser percebida como uma forma de fazer eclodir a presença desse corpo narrativo. Para Zumthor (2014, p. 79), essa implicação da presença corpórea do texto está intimamente relacionada à noção de performance, afinal, no processo de leitura, a voz que narra é prontamente formulada pelo leitor que, ao criar expectativas no processo de significação, precisa recorrer à 
corporeidade para iniciar um outro processo: o da identificação. Diante disso, a autorrepresentação, enquanto texto cuja significação evoca um corpo, pode então ser entendida como performance.

É nesse caminho que Glusberg (2013, p. 47) entende que a performance de modo algum está dissociada da questão social, uma vez que, tal como outras formas expressivas como o body art, o happening e outras estéticas eclodidas especialmente nos anos 1960, a performance buscava desfetichizar o corpo humano, substituindo o seu viés de beleza pelo seu fundamental viés de função humana, instrumento do ser humano para o ser humano.

Para Turner (1987, p. 92), performance é nada menos que uma manifestação do corpo, socialmente instalado e diretamente relacionado à cultura e ao vivido. Nesse sentido, é por meio da performance que o corpo se faz um meio de expressão, capaz de promover experiências e significações. Seguindo esse caminho, Taylor (2013, p. 208) considera a performance como uma ação interventora, atrelada ao comportamento e às práticas corporais disciplinares. Logo, num sentido amplo, performance seria o modo por meio do qual se constroem identidades, memórias, gêneros e corpos numa sociedade.

É dentro dessa perspectiva que Butler (2018b, p. 235) traz a ideia de performatividade. Para a filósofa, a utilização do corpo como forma de expressão está submetida às experiências do vivido, logo, está regida pelas regulações dos poderes normativos do meio social. O termo "performatividade" então indica o caráter performativo das práticas reguladoras presentes numa determinada cultura hegemônica, que gerencia os indivíduos e os normatiza. Dessa forma, questões de gênero são produtos do contexto de dominação das estruturas de poder que regem os corpos na sociedade. Portanto, dizer que o gênero é performativo significa que ele só é real na medida em que é performado (ibid, p. 242). Consequentemente, é por meio dessas mesmas estruturas reguladoras que os corpos buscam emancipação, ou seja, é a própria sujeição ao poder que gera a resistência a ele. Enfim, a construção do gênero e seus efeitos ocorrem ao nível "de resistências, na subjetividade e na autorrepresentação" (DE LAURETIS, 1994, p. 228).

\section{6) Performatividades narrativas e ironias de Clarice}

A narrativa de A hora da estrela é uma verdadeira ironia. Afinal, com o livro, Clarice Lispector dá uma resposta definitiva a todas as acusações da crítica sobre ela ser alienada e omissa à realidade brasileira. Em primeira pessoa, Clarice se utiliza de um 
narrador masculino - Rodrigo S. M. - um intelectual, de classe social privilegiada e acostumado a ouvir música clássica, um homem que supostamente, e de acordo com a sua própria postura crítica, tem a autoridade de contar a vida de Macabéa, mulher pobre, desajustada e insignificante.

Sei que há moças que vendem o corpo, única posse real, em troca de um bom jantar em vez de um sanduíche de mortadela. Mas a pessoa de quem falarei mal tem corpo para vender, ninguém a quer, ela é virgem e inócua, não faz falta a ninguém. Aliás - descubro eu agora - eu também não faço a menor falta, e até o que escrevo um outro escreveria. Um outro escritor, sim, mas teria que ser homem porque escritora mulher pode lacrimejar piegas. (LISPECTOR, 1998, p.13-14)

A narrativa do livro chama a atenção desde o início por conta dessa simulação inesperada ${ }^{6}$, sobretudo para os leitores acostumados à narrativa da escritora que, de modo geral, se apresenta em suas obras por meio de uma performatividade feminina. Com o narrador homem, Clarice se veste de um olhar carregado de heranças machistas e patriarcais que objetificam a mulher e a reduz em suas potencialidades. Trata-se de uma postura que desconstrói o sujeito Macabéa enquanto ser humano, uma vez que o narrador, do alto do seu ego inflado de detentor da história da moça, faz dela o que bem entende, conta tudo no seu ritmo, isto é, domina não só a personagem como também a narrativa. E enquanto faz isso, "do modo certo" segundo ele próprio, deixa claro ao leitor que é ele também a suprema onipotência (prepotência) sobre a tal mulher.

O narrador Rodrigo S. M. dialoga com o leitor e o faz à maneira de um Brás Cubas morto que conta uma história como se estivesse em outro plano metafísico. Rodrigo é homem, escritor e cheio de repertórios culturais, conhece música, cinema, vinhos... Ele revela a todo instante o quão difícil é escrever aquela história, pensa em desistir, adia os acontecimentos e sofre nesse exercício de se colocar no lugar da mulher, enfim, constrói uma narrativa repleta de angústias.

E eis que fiquei receoso quando pus palavras sobre a nordestina. $\mathrm{E}$ a pergunta é: como escrevo? Verifico que escrevo de ouvido assim como aprendi inglês e francês de ouvido. Antecedentes meus do escrever? Sou um homem que tem mais dinheiro que os que passam fome, o que faz de mim de algum modo desonesto. E só minto na hora exata da mentira. Mas quando escrevo não minto. (LISPECTOR, 1998, p. 1819)

\footnotetext{
${ }^{6}$ Para não deixar dúvidas sobre a real autoria do livro, Clarice se confessa logo na dedicatória, que tem como título "Dedicatória do autor (na verdade Clarice Lispector)" (1998, p. 9). De fato, Clarice é a autora, mas o narrador é homem e tem nome: Rodrigo S. M. O seu sobrenome não é revelado à maneira da personagem G. H. do livro A paixão segundo G. H. (1964).
} 
Rodrigo reflete sobre si mesmo ao colocar para fora a história de Macabéa e a todo instante ele reclama dela, de sua incompetência para a vida, de sua pobreza, de sua solidão, de sua inferioridade com relação às demais personagens, de sua feiura, de sua ignorância, enfim, não cansa de reforçar o abismo econômico, social e cultural que o separa dela. E essa sua alta cultura (tão importante para ele) não passa despercebida em sua narrativa, uma vez que faz questão de deixar explícita a erudição de sua própria linguagem:

Sim, mas não esquecer que para escrever não-importa-o-quê o meu material básico é palavra. Assim é que esta história será feita de palavras que se agrupam em frases e destas se evola um sentido secreto que ultrapassa palavras e frases. É claro que, como todo escritor, tenho a tentação de usar termos suculentos: conheço adjetivos esplendorosos, carnudos substantivos e verbos tão esguios que atravessam agudos o ar em vias de ação, já que palavra é ação, concordais? (LISPECTOR, 1998, p. 14-15)

É dessa forma que Rodrigo, ao reforçar uma performatividade masculina legitimada na sociedade patriarcal, conduz a um olhar direcionado sobre a jovem, ou seja: Rodrigo impõe um ponto de vista. Ao narrar ora em primeira pessoa ora em terceira pessoa, busca aprovação. Assim, ao dialogar com o leitor em primeira pessoa, estabelece confiança, aproximação e sinceridade, especialmente quando revela em seu monólogo interior as suas incertezas. E é pela confissão, algo que, conforme Butler (2017, p. 23), só se faz mediante intimidade ou obrigação, que o narrador se coloca no mesmo nível do leitor, estimulando inclusive uma identificação. Por outro lado, ao falar da vida de Macabéa, o que faz em terceira pessoa, o narrador se utiliza de sua parcialidade sobre a personagem, de modo a direcionar o olhar para dentro da luz que o próprio Rodrigo acendeu. Além disso, ao valorizar a sua rebuscada linguagem, Rodrigo é a marionete com que Clarice Lispector ironiza o padrão estético literário e narrativo supostamente só alcançado por autores "do sexo masculino".

Numa análise mais profunda, Rodrigo ama e odeia Macabéa, afinal de contas, ela escancara as fragilidades que existem dentro do próprio narrador (e da sociedade normativa e patriarcal), mas, ao menos para ele, esse é um processo epifânico, purificador e libertário. Rodrigo algumas vezes até tenta ajudar Macabéa, mas a vida dela dentro dele é tão forte e já tão predestinada que, por mais que ele desconheça os caminhos que ele próprio seguirá para torná-la explícita, já tem o conhecimento do seu destino final: a coroação, ou seja, a morte da personagem. 
Rodrigo, por exemplo, narra em terceira pessoa:

Macabéa ficou um pouco aturdida sem saber se atravessaria a rua pois sua vida já estava mudada. E mudada por palavras - desde Moisés se sabe que a palavra é divina. Até para atravessar a rua ela já era outra pessoa. Uma pessoa grávida de futuro. Sentia em si uma esperança tão violenta como jamais sentira tamanho desespero. Se ela não era mais ela mesma, isso significava uma perda que valia por um ganho. Assim como havia sentença de morte, a cartomante lhe decretara sentença de vida. Tudo de repente era muito e muito e tão amplo que ela sentiu vontade de chorar. Mas não chorou: seus olhos faiscavam como o sol que morria. (LISPECTOR, 1998, p. 79)

Macabéa é um ser que de modo geral não se expressa. Quando o faz, é só para reforçar a sua inferioridade diante dos outros, qualquer outro. Ela não é habituada ao diálogo, nem mesmo à convivência ou mesmo à própria existência no mundo, mas, por imaginar que as pessoas deviam se comunicar, iniciava conversas aleatórias e descontextualizadas, tendo como base as informações que ouvia na rádio. É o que podemos perceber no seguinte diálogo:

- Eu gosto tanto de ouvir os pingos de minutos do tempo assim: tic-tactic-tac-tic. A rádio Relógio diz que dá a hora certa, cultura e anúncios. Que quer dizer cultura?

- Cultura é cultura - continuou ele emburrado. Você também vive me encostando na parede.

- É que muita coisa eu não entendo bem. O que quer dizer "renda per capita"?

- Ora, é fácil, é coisa de médico.

- O que dizer rua Conde de Bonfim? O que é que conde? É príncipe?

- Conde é conde, ora essa. Eu não preciso de hora certa porque tenho relógio. (LISPECTOR, 1998, p. 50)

O narrador Rodrigo S. M. não interfere no diálogo, deixa fluir, de modo que leitor acaba sendo espectador direto das poucas conversas de Macabéa. Trata-se, portanto, de uma escrita capaz de ocupar diferentes níveis de discurso, sem deixar de transparecer, contudo, a ironia de Clarice Lispector, na verdade, uma espécie de personagem-deus de si mesma, capaz da artimanha de pedir passagem à normatização ao se travestir de um outro desconhecido, mas ainda assim reconhecido pela sociedade. De fato, Clarice acaba comprovando o que Butler (2018b, p. 242) vem dizer anos mais tarde: a performatividade de gênero é algo construído. A literatura então seria aqui o seu modo de construir, afirmar e reafirmar performatividades de gênero. Logo, é essa a maneira encontrada por Clarice para penetrar os espaços regidos pelas performatividades masculinas na sociedade e na literatura brasileiras de seu tempo. Enfim, é por meio de uma artificial performatividade 
masculina, isto é, performando "como um homem" que Clarice se impõe nesses espaços, numa ironia digna de sua genialidade e competência literária.

\section{Considerações finais}

Ao considerarmos o contexto literário de Clarice Lispector, escritora constantemente reeditada já há muito estabelecida no cânone, parece incongruente o fato de haver sujeições e reducionismos de sua obra por conta de sua performatividade feminina de gênero, performatividade esta especialmente marcada em sua escrita. É notável que esse cenário de abjeção da mulher na literatura brasileira só reforça o estabelecimento de uma misoginia estrutural que até hoje constitui o ambiente acadêmico e cultural do país, a exemplo da dificuldade que tem sido incluir mulheres na Academia Brasileira de Letras desde a sua fundação, por exemplo. E a própria Clarice é um exemplo disso.

Preciado (2014, p. 152) diz que as vulnerabilidades geradas pelas normas de gênero, nas quais as mulheres, por exemplo, são subjugadas e policiadas, tornam alguns corpos mais visados e controlados do que outros. O fato é que a mulher tem sido comumente subestimada e reduzida em todas as suas potencialidades. Clarice Lispector, bem como muitas escritoras mulheres, carregava em si um forte traço de estrangeiridade, não apenas por ter uma trajetória pessoal de frequentes migrações, mas principalmente por não ter alcançado o seu pertencimento e pleno reconhecimento em vida enquanto mulher, escritora e brasileira. Quando iniciou, foi subestimada; quando já era famosa, foi considerada hermética, inacessível e alienada. Ou seja, Clarice foi constantemente fadada à sombra da hegemonia do homem na literatura do país, que custosamente a reconheceu como um grande nome da nossa arte literária, tendo esse reconhecimento chegado de forma mais contundente somente após a sua morte, aos moldes de sua personagem mais icônica: Macabéa, de A hora da estrela (1977), personagem que somente na morte encontra a sua redenção.

É justamente com Macabéa que Clarice consegue revelar não apenas a representatividade da mulher brasileira, marginalizada e excluída, como também prova até aos mais céticos o seu valor e a sua importância na história da literatura mundial. Com a narrativa dessa obra em questão (escrita há mais de quatro décadas), Clarice cria uma falsa impressão de reforçar estereótipos e reducionismos da figura da mulher, mas, na verdade, nega todo tipo de reprodução desses mecanismos de invisibilidade e exclusão. E faz isso não apenas por meio da personagem central que, assim como Clarice, é mulher, 
nordestina e inferiorizada, mas também, e principalmente, ao se travestir de um narrador homem, quem supostamente teria a autoridade narrativa de contar aquela história. É desse modo irônico que Clarice se rebela contra esse regime de poder normativo que sujeita e reduz mulheres escritoras e personagens femininas.

Nesse caminho, arcaico e absurdamente atual, a obra analisada serve como exemplo de quanto as performatividades femininas são objetos de sujeição por parte da dominação masculina arraigada na sociedade brasileira, que ao deslegitimar as mulheres (enquanto personagens, escritoras), dá vazão a processos patriarcais de exclusão historicamente produzidos por questões de gênero. Entretanto, as narrativas de afirmação da mulher emanam representatividade social e, quando o fazem dentro da autoridade do vivido permitida pela autorrepresentação, estimulam olhares de pertencimento e resistência ainda mais potentes, indicando assim caminhos possíveis para uma sociedade mais plena, igualitária e livre.

\section{Referências}

ACADEMIA BRASILEIRA DE LETRAS. Clarice Lispector é tema de palestra da professora Nádia Battella Gotlib, a última do ciclo de conferências da ABL intitulado Cadeira 41, sob coordenação da Acadêmica Ana Maria Machado, 2017. Disponível em: < $\quad$ http://www.academia.org.br/noticias/clarice-lispector-e-tema-de-palestra-daprofessora-nadia-battella-gotlib-ultima-do-ciclo-de>. Acesso em: 11 janeiro de 2020.

AGAMBEN, Giorgio. Homo Sacer: o poder soberano sobre a vida nua 1. Tradução de Henrique Burigo. Belo Horizonte: Editora UFMG, 2010.

BAENINGER, Rosana. São Paulo e suas migrações no final do século 20. São Paulo: Perspec. vol.19 n.3. 2005. Disponível em: <http://www.scielo.br/scielo.php? script=sci_arttext\&pid=S0102-88392005000300 008 >. Acesso em: jan 2020.

BUTLER, Judith. A vida psíquica do poder: teorias da sujeição. Tradução de Rogério Bettoni. Belo Horizonte: Autêntica Editora, 2018a.

Problemas de gênero: feminismo e subversão da identidade. Tradução de Renato Aguiar. Rio de Janeiro: Civilização Brasileira, 2018b.

Relatar a si mesmo: crítica da violência ética. Tradução de Rogério Bettoni. Belo Horizonte: Autêntica Editora, 2017.

ELIAS, Norbert; SCOTSON, John L. Os estabelecidos e os outsiders. Tradução de Vera Ribeiro. Rio de Janeiro: Jorge Zahar Editor, 2000. 
DE LAURETIS, Teresa. A tecnologia do gênero. In: HOLLANDA, Heloísa Buarque de. (org). Tendências e impasses: o feminismo como crítica da cultura. Rio de Janeiro: Rocco, 1994. p. 206-224.

GLUSBERG, Jorge. A arte da performance. Tradução de Renato Cohen. São Paulo: Perspectiva, 2013.

GOTLIB, Nádia Battella. Clarice: uma vida que se conta. São Paulo: Editora da universidade de São Paulo, 6. Ed., 2011.

GUIDIN, Marcia Ligia. Roteiro de leitura: a hora da estrela de Clarice Lispector. São Paulo: Ática, 2002.

HALL, Stuart. Da diáspora: Identidades e mediações culturais. Tradução de Adelaine La Guardia Resende et al. Belo Horizonte: Editora UFMG, 2003.

HOLLANDA, Heloisa Buarque de. Tendências e impasses: o feminismo como crítica da cultura. Rio de Janeiro: Rocco, 1994.

KRISTEVA, Julia. Estrangeiros para nós mesmos. Tradução de Maria Carlota Carvalho Gomes. Rio de Janeiro: Rocco, 1994.

LANDOWSKI, Eric. Presenças do outro: ensaios de sociossemiótica. Tradução de Mary Amazonas Leite de Barros. São Paulo: Perspectiva, 2019.

LISPECTOR, Clarice. A hora da estrela. Rio de Janeiro: Rocco, 1998.

MENEZES, Alana Regina Sousa de. A tragédia de Clarice: mulher, punição e silêncio. In: Mulheres e a Literatura Brasileira, Macapá: UNIFAP, 2017. Disponível em: https://www2.unifap.br/editora/files/2014/12/Ebook_Mulheres-

e_a_Literatura_Brasileira.pdf $>$. Acesso em: 12 janeiro de 2020.

MOSER, Benjamin. Clarice, uma biografia. Tradução de José Geraldo Couto. São Paulo: Cosac Naify, 2011.

NUNES, Aparecida Maria. Clarice Lispector jornalista feminina. In: LISPECTOR, Clarice. Correio feminino. Rio de Janeiro: Rocco, 2006.

PRECIADO, Paul. Manifesto contrassexual. Tradução de Maria Paula Gurgel Ribeiro. São Paulo: N-1 Edições, 2014.

RUY, José Carlos. O brilho permanente da escrita feminina. Vermelho, 2016. Disponível em: < https://vermelho.org.br/2016/03/08/o-brilho-permanente-da-escritafeminina/>. Acesso em: 11 de janeiro de 2020.

SANTAELLA, Lucia. Estética: de Platão a Peirce. São Paulo: Experimento, 2000 
SANTOS, Jeana Laura da Cunha. A estética da melancolia em Clarice Lispector. Florianópolis: Ed. da UFSC, 2000.

TAYLOR, Diana. O arquivo e o repertório: performance e memória cultural nas Américas. Tradução de Lourenço de Lima Reis. Belo Horizonte: Editora UFMG, 2013.

TURNER, Victor. The anthropology of performance. In: The anthropology of performance. Nova York: PAJ Publications, 1987.

ZUMTHOR, Paul. Performance, recepção e leitura. Tradução de Jerusa Pires Ferreira e Sueli Fenerich. São Paulo: Cosacnaif, 2014.

\title{
FOREIGNITY AND SELF-REPRESENTATION AS NARRATIVE GENDER PERFORMATIVITY IN CLARICE LISPECTOR
}

\begin{abstract}
The article initially seeks to relate Clarice Lispector inside the notion of foreignness, as proposed by Julia Kristeva, to exemplify the clandestine nature of the woman writer in patriarchal Brazilian society. In this sense, the male/female narrative game of $A$ Hora da Estrela (1977) is analyzed by the notion of performativity, proposed by Judith Butler, to understand self-representation as a valid tool that echoes the feminine statement in the face of this historic abjection. Finally, the character Macabéa is pointed out as an ironic reaction of the author to the structural misogyny of the Brazilian literature, as the character deterritorializes the usual woman's reductions and has the legitimacy of her existence conditioned to the narrative authority of a male self, which is actually Clarice Lispector.
\end{abstract}

\section{Keywords}

Foreignness. Literature and Resistance. Self-representation. Performativity. Clarice Lispector. 